Saint Louis University School of Law

Scholarship Commons

All Faculty Scholarship

2016

\title{
Crowdwork, Corporate Social Responsibility, and Fair Labor Practices
}

Miriam A. Cherry

Saint Louis University School of Law

Winifred R. Poster

Washington University in St. Louis, College of Arts and Sciences

Follow this and additional works at: https://scholarship.law.slu.edu/faculty

Part of the Labor and Employment Law Commons

\section{Recommended Citation}

Cherry, Miriam A. and Poster, Winifred R., Crowdwork, Corporate Social Responsibility, and Fair Labor Practices (May 8, 2016). Research Handbook on Digital Transformations, Chapter 14.

This Article is brought to you for free and open access by Scholarship Commons. It has been accepted for inclusion in All Faculty Scholarship by an authorized administrator of Scholarship Commons. For more information, please contact erika.cohn@slu.edu, ingah.daviscrawford@slu.edu. 
Crowdwork, Corporate Social Responsibility, and Fair Labor Practices

Miriam A. Cherry and Winifred R. Poster

Chapter Fourteen, Research Handbook on Digital Transformations (F. Xavier Olleros \& Majlinda Zhegu, eds., Edward Elgar, forthcoming 2016).

\section{INTRODUCTION}

In the science fiction story The Water Thief, Alastair Reynolds (2013) tells the story of Soya Akinya, who ekes out a living as a crowdworker in a refugee camp sometime in the future. Donning virtual reality equipment, Soya enters the 'global workspace' every day, performing remote, 'virtual work', mostly controlling underwater repair robots. Some tasks pay better than others, and some have more flexible hours. The terms, conditions, pay and skill levels are all based on fluctuating supply and demand, with a low prevailing wage. Employers have many rights in this science fiction story; workers, who go from one precarious gig to another, have relatively few. One day, despite her lack of experience, Soya is placed in a scenario that requires her to engage in a perilous search and rescue mission on the moon. When her employer gives the command to abandon the man she rescued, Soya balks. In response, not only does the employer refuse to pay for Soya's time, but her skill and trust levels plummet. Finding that she has become a pariah in the global workspace, Soya is forced to quit and must find another way to earn a living.

While Reynolds' science fiction story portrays a dystopian vision, it presents us with many of the problems with crowdwork today. The transformation of human work is one of the defining features of the current digital transition. Crowdsourcing, in which technology allows large numbers of people to contemplate or solve a problem, is commonly noted as a hallmark of the Internet era. While crowdsourcing is often associated with voluntary activities such as editing articles on Wikipedia, technology has also allowed large numbers of people to perform work tasks for remuneration. Paid work that may be performed by hundreds or thousands of workers is known as crowdwork (Kittur et al., 2013).

Crowdwork is a paradox. On the one hand, crowdwork presents great potential for workers and employers alike, making work increasingly more efficient and enabling 
globalization and cooperation between workers on an unprecedented level. On many crowdsourcing platforms, large tasks are disaggregated, broken down, worked on by individuals, and then reassembled by computers in an efficient way. As described by Jeff Howe (2006), crowdsourcing takes the products of many workers to create something greater than the sum of its parts. Crowdworkers on websites like Innocentive may enjoy the opportunity to work on complex and difficult engineering problems. On other crowdsourcing websites, graphic designers compete and bid on graphic design work, and may be able to find new markets and customers for their creative endeavors. Crowdsourcing, combined with automation, may lower start-up costs, enabling the growth of an innovative global economy. As a co-founder of Netscape has written: 'On the back end, software programming tools and Internet-based services make it easy to launch new global software-powered start-ups in many industries - without the need to invest in new infrastructure and train new employees' (Andreessen, 2011).

On the other hand, some forms of crowdwork seem to be engaging in a 'race to the bottom' with declining labor standards. On Amazon Mechanical Turk (AMT), for example, workers are paid a small amount for their participation in certain simplistic tasks that are later consolidated, often calculated in pennies and paid in Amazon credit. While the hourly return on these tasks would depend on how quickly a worker would be able to complete them, it is difficult for a worker to perform enough of them to earn the minimum wage in the United States (Stross, 2010). The tasks that Turkers perform are often simple, repetitive and low-skilled, such as writing a description of a photo. According to the terms of use, requesters have many rights on the Mechanical Turk website; Turkers, on the other hand, have far fewer.

Meanwhile, in large US cities, website and mobile platforms that match workers with tasks, including driving, home repair and grocery shopping, are proliferating. Anyone with the spare time, equipment and skills can participate on cellphone applications ('apps') such as Lyft, Uber, Handy or Instacart and make money by driving, doing home repairs or delivering groceries. Many of these service platforms stress the value of community and people helping each other through the 'sharing economy'. While not purely computer based, these on-demand platforms raise some of the same labor problems and concerns that are present on the crowdworking websites. They are, in fact, a form of crowdwork despite the fact that part of the work (the driving, grocery buying) takes place in the real world. 
This chapter seeks to reconcile the paradox of crowdwork by articulating 'best practices', especially for those forms of crowdwork that involve lower-skilled forms of work. We are not the first to have commented on the need for improved cyber-labor practices. Indeed, in 2008 Professor Lily Irani and Six Silberman developed a program known as ‘Turkopticon', which allows workers on AMT to rate their employers. Further, in 2010 a group of students at the Berkman Center for Internet and Society at Harvard Law School developed a draft paper on fair standards in cloud computing. ${ }^{1}$ Although this work was not published, it was circulated among those who had been writing and thinking about the topic, including one of the authors. Kittur et al. (2013) also have asked important questions about crowdwork, looking to improve these jobs for the future. In light of the June 2015 decision from the California Labor Commission, holding that an Uber driver was an employee and entitled to the protections associated with that status, this is the right time to talk about ethical labor and crowdsourcing.

We seek to link ethical labor practices in virtual work with well-established notions of corporate social responsibility (CSR). CSR principles hold that businesses should take into account notions that include not only profit, but also concerns for the environment and for worker well-being and fair treatment. Crowdwork already presents a myriad of environmental benefits, as the use of technology and remote work has the potential to reduce fuel from daily commuting. Socially responsible labor practices would stabilize and legitimize crowdwork. As crowdwork sometimes involves back-office work and is largely invisible to consumers, it is especially important to call attention to this issue.

Note that throughout this discussion we focus for the most part on lower-skilled, lower-wage crowdwork as these types of work point out the flaws in crowdwork systems, and involve the most vulnerable workers. That said, we recognize that not all crowdwork has the same types of labor concerns. For example, highly-skilled computer programmers may use sites like TopCoder and Kaggle, which run programming competitions and offer lucrative prizes. But the presence of high-end crowdwork does not negate the problematic nature of the labor practices at the low-end. In fact, some authors reckon that the ongoing acceleration of technological advancement will only amplify the polarization of labor markets and prevailing income inequality.

We begin with an overview of labor, information and ethics from a sociological perspective, which informs the rest of the chapter's analysis. The chapter then turns to the three tenets of best practices for crowdwork. First, we set out the concerns around fair wages for crowdwork. Second, 
we discuss the need for transparency, encompassing the idea of fully disclosing information about tasks, including fair estimates of time and wages, and disclosing to micro-labor workers the larger goals their work contributes to. Finally, we discuss the importance of due process, that is, that ratings of workers online should be based on fair criteria, and that there should be some appeals process for non-payment of wages or poor ratings. While not the only considerations, implementing these practices would surely result in a better working environment online.

\section{A SOCIOLOGICAL OVERVIEW OF LABOR, INFORMATION AND ETHICS}

\section{Information Society}

Scholars since Daniel Bell (1976) have talked about the rise of the information economy. Unlike jobs in the industrial era, these post-industrial jobs use information as a raw material for the tasks. Castells (2010), in particular, has charted the path of an 'informational society', in which one-third of US jobs have become information-related, starting in the 1990s. They are also among the fastest growing sectors of the labor force. STEM occupations, for instance, in science, technology, engineering, mathematics and social science, are a critical component of new jobs created between 2008 and 2018 (Carnevale et al., 2010). STEM-focused work has a unique function: 'they generate the technological changes that shape all other occupations' (p. 52). Finally, an important marker of the information society is the growth of the knowledge economy and knowledge work - the work that produces information (Arvidsson et al., forthcoming).

Less discussed or theorized, however, is another dynamic of the informational society: the creation of an underlying digital infrastructure within which employment occurs. This digital infrastructure is more than just a virtual workplace. It is an organizational restructuring of how work occurs, and an embeddedness of labor in the processes of software code. As we will illustrate, this has led to new patterns of employment, and new relations between employers and employees. Hosting sites, platforms or cellphone applications ('apps') now facilitate work. These platforms are clustered around particular tasks, skills and industries (Table 14.1). 
Some crowdsourcing websites and apps have a limited role, which is to match workers and those looking for work. Other companies, like AMT and CrowdFlower, have a larger role in employment. Work is done online, sometimes on the platform itself. As the work that is performed is digital, the platform becomes the job site.

Another feature of the digital infrastructure is a predominance of computer code in mediating work relations. Here, we are referring to the software through which employees carry out their work. Aneesh (2009) calls this process 'algocracy', noting the ways that algorithms are taking over many organizational functions that have traditionally been the domain of managers. These programs perform a variety of supervisory tasks from the mundane to the sophisticated: assigning tasks to workers, speeding up work processes, determining the timing and length of breaks, monitoring quality, and much more. They make crucial on-the-spot decisions about individualized employees and what they are doing. Labor practices that were run through bureaucracy and other organizational control regimes are becoming embedded within the computer programs. Workers are directed by imperatives from algorithms, which replace the traditional external schemes carried out by managers.

$<\mathrm{b}>$ Precariousness

Understanding the growth of crowdwork requires attention to a second trend: the expansion of precarious labor (Ross, 2009; Vosko, 2006). By 'precarious', scholars are referring to labor that is more than just part-time and temporary. The notion encompasses a deeper undercutting of reliability and security in labor systems.

Kalleberg (2009) defines it as 'employment that is uncertain, unpredictable, and risky' (p. 2). Stone (2004) refers to it as 'work that has no explicit promise of continuity' (p. 72). The critical factor here is that it applies to the gamut of occupations. Even those that are 'steady, fulltime', may lack an 'explicit or implicit promise of job security' (Stone, 2004, p. 72). This degradation of labor is felt by the full range of workers, from fast food service (Ehrenreich, 2010; Newman, 2000) to engineering consultants (Barley and Kunda, 2004).

Kalleberg charts dramatic trends. Through precarious labor systems we are seeing: an increasing likelihood of unemployment, a growth of general job insecurity, expanding contingent and non-standard work, and risk shifting (that is, the transfer of labor expenses like health insurance and pensions from the employer to the employee). Impacts on the daily lives of lower- 
skilled, lower-income workers have been severe. Lambert (2012) notes that schedule unpredictability wreaks havoc on family life. For working parents, it means difficulty in arranging childcare and doctor's appointments, and an obstruction of household routines that are necessary for healthy childhood development. Furthermore, precarious labor can put workers in a trap: while you need several jobs to survive, having a second job is something that can get you fired from the first (Tirado, 2014). Precarious labor has gained ascendance in service and retail jobs, in which women and people of color predominate (Lambert et al., 2014). However, one of the important markers of precarious labor is how it is steadily moving up the occupational ladder (Kalleberg, 2009). Increasingly, jobs in knowledge work and information are experiencing precariousness as well.

\section{Crowdwork as a New Phase of Employment}

At the intersection of the information society and precarity lies crowdwork. In this new form of labor, tasks are miniaturized, broken down, and tradable online for the tiniest parts. Micro-labor is identified for its small scope, short duration, tiny output and limited remuneration. At the same time, it is characterized by an opposing feature: massive scale. Employees doing tiny jobs are being hired and aggregated in large numbers. For crowdworking platforms and those who request work, the gain is substantial productivity out of legions of low-paid micro-workers. For workers, however, their livelihoods are dependent more and more on searching and carrying out tiny tasks.

This foray into crowdwork represents a new phase in employment. To illustrate what this means analytically and in practice, we outline these transformations in Table 14.2. Spinning off the classic model of 'industrial' employment, the information society has spurred two subsequent stages. The next phase can be seen in what Stone (2004) calls a 'digital' model. We elaborate her conceptualization by adding a third stage: a 'crowdsourced' system of employment.

\section{<INSERT TABLE 14.2 ABOUT HERE>}

Part of the distinction between these systems is chronological and production-based. Industrial employment refers to the factory era of the late nineteenth and early twentieth 
centuries, when assembly lines and scientific management of labor were developed. The digital era, as Stone (2004) defines it, refers to the mid- to late twentieth century, when computers and the Internet became 'the central nervous system of global production networks' (p. 5). Although there was a shift towards fluid workplaces and permeable borders between firms, there was still value placed on the intellectual capital of employees. The crowdsourced era, as we argue, takes off in the twenty-first century with the spread of mobile computing and the emergence of microlabor websites. Here, the foundation and centrality of the firm as the site of work vanishes altogether, radically altering the relation between employee and employer.

The more fundamental difference between these systems, then, is in the construction of the labor and its conditions. While previous models had some modicum of stability and secure remuneration, the latest model is marked by rapid fluctuation, decreasing authority, and declining pay. The impact of precarity, especially within the context of information technology, is striking here. If the 'digital' era broke schedules down into part-time shifts, 'crowdsourcing' breaks it down even further. It moves from 'project' based work (with coherent aims and stages) occurring over a duration of weeks, months or years, into 'task' based work (the purpose of which may not ever be explained by employers) occurring in just hours, minutes or seconds. Micro-labor is described by the Wall Street Journal as 'taking the division of labor to onceunthinkable extremes' (Glazer, 2011).

In many ways, then, low-skilled crowdsourcing is a return to industrial (or even preindustrial) systems - piece rate pay and highly rigid control systems, for example. While some observers describe these media sites as efficient in matching employers and workers, others point out how they drive down wages. Researchers find that large numbers of workers rely on their wages to make ends meet (Ross et al., 2010), without benefits like sick pay, pensions or health insurance. Sociologically, these are 'bad jobs' (Warhurst et al., 2014): no training, low advancement, low pay and lack of upward mobility.

Given these changes, scholars are now calling for an 'ethics' of micro-labor and crowdsourcing (Irani, 2013; Irani and Silberman, 2013). In 2013, we convened at the NSFsponsored Socio-Technical Systems Summer Institute with colleagues Lilly Irani, Six Silberman and Cecilia Aragon to discuss the ethics of micro-labor. Our interest was in putting forth an agenda for ethics in crowdsourcing. This was a broad discussion that included the design of 
platforms that operate at scale and still support fair social relations and crafting systems and policies that represent the interests of employers, employees and host providers. Accordingly, our analysis here is intended as a step in the direction of defining and putting into practice an ethics of crowdwork. The following sections concentrate on an agenda for ethical crowdwork: fair wages, transparency and disclosure.

\section{FAIR WAGES}

As crowdwork has proliferated, so too have news stories recounting extremely low wages for workers on these websites. Marvit (2014) told the story of two workers attempting to work fulltime on AMT; both struggled, unable to earn minimum wage. Similarly, journalists in the United Kingdom wrote about crowdwork, noting they earned less than the equivalent of $\$ 2 /$ hour. $^{2}$ One of the authors had a similar experience when she and her research assistant undertook tasks on AMT. While these stories are anecdotal, the piecework nature of low-skilled crowdwork means that sub-minimum wages are, if not guaranteed, certainly predictable.

A looming legal question is whether the Fair Labor Standards Act (FLSA), the US minimum wage law, either does or should apply to crowdwork. In 2013, workers from the crowdsourcing website CrowdFlower brought a lawsuit in federal district court alleging violations of the FLSA. ${ }^{3}$ While the FLSA applies to 'employees', it does not cover 'independent contractors'. The legal classification of crowdworkers as either employees or independent contractors was to be one of the most important legal issues in the case, Otey v. Crowdflower. The parties, however, reached an out-of-court settlement and the case was dismissed. This meant that the court never reached the true merits of the legal question. Thus, the legal and policy questions surrounding minimum wage for crowdwork in the United States have remained unresolved. $^{4}$

When the US Congress passed the FLSA in 1937 to prop up the economy during the Great Depression, America's workers were most often physically present at an employer's place of business, leaving little question that they were 'working' and that they were 'employees', and thus entitled to the minimum wage. As we noted in the last section, work has been transformed by technology in the intervening years. With their own computers and Internet connections, 
crowdworkers may perform computer tasks on someone else's behalf often while at home or in another location of their choice. Crowdwork may in some instances be repetitive and boring, but in other instances crowdwork may be engaging or even look like a game, contest or creative endeavor, and in other instances, it may feel as if workers are building community or helping neighbors in their local area. Crowdwork that involves computer work can be performed remotely, anywhere in the world. The mobile nature of crowdwork makes it more susceptible to outsourcing and downward wage pressure.

The requirement to pay the minimum wage under the FLSA depends on whether a given worker is considered an 'employee'. An 'employee' is 'any individual employed by an employer'. The FLSA defines 'employ' as 'to suffer or permit to work'. ${ }^{6}$ While this definition is extremely circular, in the Otey v. Crowdflower case, the salient issue that emerged in the litigation was whether the crowdworkers were 'employees' (subject to the FLSA) or independent contractors (not covered by the FSLA).

Under US law, whether a worker is an employee or independent contractor is determined through a multifactored test dependent on the facts of the relationship. ${ }^{7}$ The multifactored test derives from the case law and decisions on agency law, and focuses on a principal's right to control the worker. Some of the factors for finding employee status are whether the employer may direct the way in which the work is performed, determine the hours involved, and provide the employee with direction. ${ }^{8}$ On the other hand, elements that lean toward independent contractor classification include high-skilled work, workers providing their own equipment, workers setting their own schedules, and getting paid per project, not per hour. In addition, courts examine the economic realities of the relationship to determine whether the worker is exhibiting entrepreneurial activity, or whether the worker is financially dependent upon the employer (Stone, 2006). The labels the parties choose to affix to their relationship are a factor but not dispositive.

Crowdwork presents an interesting issue because some of the factors in the control test point toward an employee relationship while others are reminiscent of an independent contractor relationship. On the one hand, crowdworkers share some of the characteristics of independent contractors. Crowdworkers set their own schedules and have a great deal of ability to come and go from the virtual environment than do real workers tethered to a workplace desk or factory 
floor. Crowdworkers also use their own computer equipment and Internet connections, and are paid by the job. Further, the clickwrap on many websites indicates that workers are 'independent contractors'.

On the other hand, many factors seem to indicate an employment relationship. With lowskilled crowdwork, the opportunity for entrepreneurship, and with it risk-and-reward, is barely, if at all, present. There is a great deal of control as well as digital surveillance. The terminology in terms of service on websites, often known as End User License Agreements (EULAs), is far from dispositive, as such online contract are known to be extremely one-sided and are construed against the drafter. The possibility for exploitation is high, and low-skilled workers are those that are most in need of FLSA protection.

Logically, a decision that the FLSA would not apply to crowdwork could only be justified by drawing a distinction between workers that are remote and set their own schedules and those performing the exact same work tasks in an office. That distinction is not a principled one. Remote work from a computer platform is still work. It makes no sense to deny a group of workers the protection of the law because they use a computer as their machine, rather than a 1930s factory machine that sits onsite. Data entry, if it took place in an office, would be a covered activity under the FLSA. Similarly, if someone is driving 40 hours a week and receiving referrals from Uber's app, it is difficult to see any difference between that arrangement and driving for a taxicab company. Rather, the difference in these scenarios is the difficulty of applying a Depression-era statute to modern day situations involving technology.

That said, the outcome of future litigation is unclear based on the indeterminacy of the 'employee' versus 'independent contractor' distinction. It is important, therefore, to consider the larger policies surrounding minimum wage. Making the argument for increased government intervention in the economy is always controversial, and may invite criticism from libertarians as well as those who wish to promote the development of crowdsourcing technology. ${ }^{9}$ Although sympathetic to arguments that the technology needs time and freedom to develop, ${ }^{10}$ some authors believe that the interests of other stakeholders also have to be properly balanced.

The history of the FLSA supports an expansion of its coverage to crowdworkers. As part of the New Deal economic programs designed to lift the country out of the Great Depression, the goal of the FLSA was to prop up wages and provide a basic level of support to workers. During 
that period, approximately one in every four workers was jobless; far more workers were underemployed (Mitchell, 1969; Rejda, 2012; US Department of Labor, 2001). The high supply of labor, coupled with slumping demand, resulted in increasing competition for available work. Workers' wages declined, resulting in a lack of purchasing power. As a result, fewer goods were sold, and the low wages perpetuated a downward economic spiral (Edsforth, 2000; Levitan et al., 1993). The intervention of the FLSA in the market was therefore a cornerstone of the New Deal economic legislation. And thus the question of whether a minimum wage was needed was already decided many years ago, and resolved in favor of worker protection. ${ }^{11}$

In some ways, a push for a minimum wage for crowdwork seems a modest request. Minimum wage is low, and many have questioned whether it is adequate. In her well-known book, Nickled and Dimed, writer Barbara Ehrenreich (2010) attempted to live in various US cities with the money earned from minimum wage jobs. Ehrenreich could barely find the money to cover basic shelter and food costs. Just this past year, US fast food industry workers have campaigned for a 'living wage' of US $\$ 15$ per hour, approximately double the current minimum wage. ${ }^{12}$ Current crowdworkers count themselves lucky to even come close to the minimum wage.

In light of the Otey v. Crowdflower and ongoing Uber litigation, it would make sense for crowdsourcing platforms to implement fair wage practices. This would be beneficial to these sites as it would stabilize and legitimize their business models. The threat of litigation and an adverse ruling by the courts is not a matter that crowdsourcing platforms probably wish to risk as they are seeking to establish a market niche for themselves. Incorporating corporate social responsibility, in the form of a minimum wage for workers, would be appealing to certain groups of consumers and investors.

\section{DISCLOSURE AND TRANSPARENCY}

The next part of best practices is classified under the rubric of transparency and clear disclosure. Transparency in crowdwork encompasses a number of concepts. First, transparency is needed for workers so that crowdsourcing websites provide clear information about tasks, fair estimates of time and wages. In some instances, where work is gamified, it may be important to inform users 
that they are actually working. In addition, it is important that workers are given the bigger picture of what the projects they are working on actually concern. Finally, transparent labor practices are important for consumers and employers because the nature of virtual work tends to obscure the conditions under which labor is performed. This issue is akin to more long-standing problems that exist in global supply chains, where prison, sweatshop and child labor may be obscured or hidden from consumers.

Transparency is a complement to adequate wages; full disclosure helps workers better understand the tasks that they have been assigned. On some crowdsourcing websites, it is not clear to potential workers who might sign up for a task, what exactly is required to complete the task. So, for example, a task might be listed one way in the description, but when the worker accepts the task and actually starts doing the work, it is more time consuming or more difficult than it was described. This has the net effect of decreasing wages overall, but more problematically, it can be potentially misleading.

Other times workers may be unaware that they are even working at all. Such is the case when work is 'gamified', in other words, when work is structured to make it look like a game or contest (Cherry, 2012). Such forms of disguised work are often not disclosed to the user who is doing the work. For example, many websites use 'captcha' software in order to make sure that users are real instead of an automated program that will spam the website. Users understand the purpose of the captchas and transcribe a word or phrase to prove that they are real. What most users are unaware of is that when they do the transcription, they are actually doing crowdsourced work. Users in their transcribing are doing optical recognition work that computers cannot do. A captcha is of small time value and, indeed, serves the purpose of weeding out spam robots. Thus as a de minimis intrusion, a captcha is hardly objectionable, but it would be good if the other uses of the captcha were fully disclosed. Other instances of gamification might involve a more elaborate construct or a great deal more of a user's time. In all these instances, being upfront with users will allow them greater autonomy and choice.

In some instances, the best practice of transparency relates to the overall project and the 'big picture' of the work that is being performed. If work is manipulated and broken down into its smallest components, crowdworkers have no idea if the overall aim is toward a goal they agree or disagree with. As some number of crowdworkers may be 'killing time', and others will 
volunteer for work that they deem worthy (for example, search and rescue missions to find the downed Malaysian jetliner), others might choose to reject work if they find it objectionable. So, for example, many might happily volunteer to search a portion of the bandwidth or cosmos for signs of intelligent alien life, but find it objectionable to scan the borders for other types of aliens.

People bring their own morals and sense of what they wish to support when they decide which projects they may want to work on, either as paid workers or volunteers. The point, however, is that the individual should have the right to decide to participate, upon hearing of the overall project goal. In some instances project goals are not fully revealed. This can lead to confusion, frustration, and outright anger in some instances.

It is well known that some jobs are considered 'less desirable' or perhaps may even be in some ways morally repugnant. For example, during the days of tobacco litigation, some law firms paid attorneys more money to defend tobacco companies than they would pay for more benign forms of litigation. The idea of defending tobacco firms was repugnant to a group of attorneys and thus there was a shortage of supply. Increased wages were instituted in order to keep the supply of attorneys high.

Recently, researchers Pörtner, Toomim and Hassairi sought to test the link empirically by conducting a labor experiment on AMT. ${ }^{13}$ The researchers wanted to determine if work that was seen as morally repugnant would retain fewer workers than a more benign job. To test their hypothesis, the researchers assigned workers on AMT a task, writing a letter of support to a prison inmate. This sounded fairly innocuous as a task on the initial screen. When some workers clicked on the task, they were shown a screen that discussed how prisoners feel isolated and needed support. The workers were told to write a letter of support to someone who was in jail for a 'felony', but what the crime actually consisted of was not specified.

Another group of workers, however, received the same description but were told that the inmate they would be writing to was a convicted child molester. Unsurprisingly, a larger number of these AMT workers dropped out of the task compared with those who were given a more benign description. In all of these instances, the work was not genuine. No one was actually sending letters of support to anyone in jail; the descriptions of the work were artificially manipulated to measure the repugnance of the task. 
The research paper, which appears to have received IRB approval, in fact stressed the ignorance of those doing the work. For example,

[t]he worker is unaware that the offered job is part of an experiment and is always presented with the same set of circumstances based on the worker ID number (each worker on Mechanical Turk has an unique ID number).... Feedback received from workers show no suspicion that the jobs are artificial. (Pörtner et al., forthcoming, p. 10)

Workers, who were unaware that they had been part of an experiment, were shocked and upset when they found that their feelings had been manipulated as part of an experiment to measure repugnant work. Needless to say, they did not appreciate being subjected to this task solely for the purpose of an experiment. They complained vociferously on the Turkopticon web boards about these types of tasks and the manipulation being used on workers just trying to make a living.

It is true that most workers do not have a large 'say' over how their work is ultimately used. For example, a research scientist might make a discovery that eventually could be used for a life saving cure or could be used for biochemical warfare. A particular worker's ideas and effort could be used for good or ill, all depending on whose hands that work falls into. One could say that in large part, by selling one's labor, one cedes the control over how the fruits will be used unless there is a contract or prior agreement.

That being said, crowdwork is different in some ways from the other forms of work that preceded it. Unlike other forms of work where the employee may be able to ask questions of the employer about the bigger picture and can make decisions, online there may not be this type of opportunity. Information about the type of work and how the crowd's work will be used should be available to workers.

The value of transparency also should extend to consumers. Many deceptive and exploitative forms of labor are emerging behind the systems of crowdwork. As an employer, if you don't know who the employees are, how can you practice ethical hiring from a crowdwork website? As a consumer, how are you supposed to know that you're getting an ethical service or product? 
Global supply chains can obscure labor practices by dispersing businesses geographically and breaking down the operations, functions and participants into many segments. Through global labor arbitrage, firms move their jobs to countries where hiring workers is less expensive, where they can save on rent and physical infrastructures, and where they receive exemptions from legal regulations. Multinational corporations operate in multiple jurisdictions to take advantage of wage differentials. Firms may also outsource and subcontract parts or divisions of their operations to third party firms, often across borders.

The phenomenon is now standard for business practice: 80 percent of Fortune 500 companies now outsource some of their functions abroad, and 50 percent outsource to India in particular. In our book project on Invisible Labor with colleague Marion Crain (Crain et al., forthcoming), we have been documenting how these processes shield labor from the view of consumers and the public. Making workers and work more visible can be a crucial step towards fair market practices.

Unfortunately, it often takes egregious infractions of labor standards or disasters to uncover these cases and compel transparency to the public. For example, garment makers in Dhaka, Bangladesh had been operating under dangerous conditions for decades, leading to a fire in 2012, and then a few months later, a building collapse that left over 1100 workers dead (Greenhouse and Harris, 2014). Observers called it 'the worst disaster in garment industry history'. These employees, mostly female and earning the equivalent of $\$ 37$ dollars a month, were sewing clothes for labels such as Walmart, Target and Gap (Muhammad, 2011). Yet many consumers in the US and Europe were unaware of this situation, on many levels: the conditions of work, the risks employees faced on a daily basis, and the link to widely distributed clothing they were wearing. In turn, they became outraged with the news and organized boycotts of the brands.

Sociologists have noted that there are easier ways to achieve transparency rather than waiting for disasters. Through transparency, firms can mobilize an untapped potential for consumer support. Kimeldorf and colleagues (2006) find that consumers will pay more (up to a point) for ethically produced goods. In this study, retailers placed garments with sweatshop-free labels next to ones without. On average, 30 percent of the customers were willing to pay a higher price for the ethically-produced clothing. National surveys provide broader evidence of this 
tendency; 68 percent of respondents stated that they would pay up to 20 percent more for ethically produced goods.

This evidence confirms, according to Kimeldorf et al. (2006), that:

majorities of Americans [are] willing to pay more for apparel made under good working conditions. Such support for sweat-free goods suggests that conscientious consumers could become a powerful force for improving pay and workers' rights in the apparel sector, where workers are often paid less than 10 percent of the final sales price (p. 28).

Yet the key to activating this potential in consumers is transparency: 'this will only happen if market and regulatory institutions can be made to provide would-be conscientious consumers with accurate information on the labor conditions under which products are made. Without this information, such people cannot act on their convictions, however strong.' (Kimeldorf et al., 2006, p. 28).

There are indications that businesses are seeing the benefits of labor transparency for relations with their customers. Some global companies are using new technological strategies to make the production processes of their goods more transparent in a literal sense - visually. As Poster writes about in her research on surveillance, retail businesses in the UK are placing webcams on the overseas manufacturing sites of their subcontractors, in order to reassure their local customers of a sweatshop-free product (Poster, n.d.). In sum, there are potential gains with transparency: for consumers who are acting upon their ethical conscience, for businesses to improve profits and attract customers, and for workers who reap the benefits of better working conditions.

\section{DUE PROCESS}

Returning to the Reynolds science fiction story, after Soya refuses to abandon the helpless man in the course of her work, she certainly must face the consequences. Soya finds herself without pay for her time. She is also demoted, and all of the skills she has worked so hard for over a period of years completely erased within seconds. Essentially, Soya suffered reprisal, without an 
opportunity to explain her actions. She was blackballed from the global workspace without any recourse or process. Again, while a work of dystopian fiction, the story points out areas in current crowdwork that call for our attention. Basic fairness principles should be employed before workers are deprived of pay for work rendered, or when workers are given a poor rating that may impact their ability to find other work.

Currently, under various terms of service on websites, requesters/employers have almost unlimited discretion to rank and assess workers. The terms of service of Amazon Mechanical Turk, for instance, allow Requesters many such rights, including the ability to withhold payment for work that is not done correctly. However, since the determination about whether the work is done correctly is solely within the discretion of the Requester, this potentially raises the problem of arbitrary rejections. In such an instance the worker has then spent their time for no remuneration, and is left with no redress.

One major complaints of Turkers, documented by Irani and Silberman (2013), is that workers lack any kind of return access to a system that would allow them to contest or dispute poor rankings given to them by employers in a fair and meaningful way. Granted, a feeble system for complaint exists in that workers may send requesters an email message. Yet there is no requirement for employers to respond, and in fact, given the massive numbers of workers on the platform, the idea of individual responses is cost-prohibitive. Obviously cost is a factor; if every poor ranking could be contested, that would negate in many ways the effectiveness of the platform. But even given these efficiency arguments, to put the decision about payment, rankings and skill levels solely in the hands of those who are providing payment creates a power imbalance.

The discretion of the employer to pay or to reject work at its sole discretion would be unsanctioned conduct in the real world. In US jurisdictions, work - even if done incorrectly or not all that well - is still considered 'work' and payment to workers is still due. Employers are generally accountable for monitoring work, redirecting the worker, or even stopping the worker if the work is not being provided in a competent or satisfactory manner. Wage statutes do not generally allow the employer to hire the worker, have them continue for a period, and then, after the work is completed, not pay the worker. State wage laws also provide that payment must be provided on a timely basis. Alleged violations of wage laws are normally reported to the State 
Attorney General's office and investigated as wage theft. In addition to the wages and back pay due to the aggrieved workers, fines and penalties may be levied against non-compliant employers.

Currently, no standards define what 'quality work' on crowdsourcing platforms means. Nor are there uniform standards for timely pay or withholding pay. Platforms may differ in these rules and policies, adding yet another layer of potential arbitrariness. One way to address this would be a mechanism for workers to 'self report' on their own progress, subject to a check. Input could also be sought from workers on what a 'good task' includes or encompasses. But self-reporting would still have its limits and even with uniform standards, disputes could arise.

To borrow concepts from the unionized work force, industrial due process would embrace both fairness to the worker and preserve the efficiency that crowdsourcing technology affords. Industrial due process encompasses notice to both parties, the process of having the dispute heard by a neutral, and the articulation of a rationale or reasoning behind the ultimate decision.

Some options to obtain this kind of due process might be a mediation or arbitration system, set up and conducted by a neutral third party. Other options might be to establish a 'jury' of Turkers who would understand the system and enforce mutually agreed-upon rules for items such as appeals of poor ratings or skill levels. Such systems currently exist in other online settings, such as the online game League of Legends.

Wage disputes as well as skill disputes would be sent to an alternative dispute resolution (ADR) system. ADR systems can potentially be inexpensive and fast ways to resolve online disputes. Safeguards would have to be followed in order to ensure that those who hear the dispute are neutral and have the appropriate expertise in labor disputes to understand the problems presented by crowdwork. Provided these safeguards are followed, ADR could provide a meaningful and efficient forum for protecting the interests of both workers and requesters. More egregious or intentional violations of the rules or laws would still be referred to outside governmental authorities or be heard by courts. But most disputes could potentially be resolved by a form of ADR.

\section{CONCLUSION}


The Reynolds story presents a dystopian view of crowdwork, one in which workers are treated as anonymous cogs in a machine. Wages are a race to the bottom, only exacerbating inequality. Work is not fully explained, leading to moral quandaries, and employers have nearly boundless discretion in ranking employees, even for arbitrary and capricious reasons. But this bleak future need not be ours.

If we want a different vision for the crowdworkers of the future, we must have the courage to reimagine the systems and policies now in place. If fair labor practices are put in place, we might all enjoy the benefit from fast, efficient, targeted work. The values of fair wages, transparency and disclosure, and due process are crucial to the future of crowdwork.

\section{REFERENCES}

Andreessen, M. (2011). Why software is eating the world, Wall Street Journal, 20 August. Accessed at http://www.wsj.com/articles/SB10001424053111903480904576512250915629460.

Aneesh, A. (2009). Global labor: algocratic modes of organization. Sociological Theory, 27(4), $347-70$.

Arvidsson, A., Gandini, A. and Bandinelli, C. (forthcoming). The ethics of self-branding among freelance knowledge workers. In M. Crain, W.R. Poster and M.A. Cherry (eds), Invisible Labor. Berkeley, CA: UC Press.

Barley, S.R. and Kunda, G. (2004). Gurus, Hired Guns, and Warm Bodies. Princeton, NJ: Princeton University Press.

Bell, D. (1976). The Coming of the Postindustrial Society. New York: Basic Books.

Bingham, M. and Dunn, J. (2009). Wanted: digital drones to earn 1/2 p an hour. Sunday Times, 11 January.

Carnevale, A.P., Smith, N. and Strohl, J. (2010). Help Wanted: Projections of Jobs and Education Requirements Through 2018. Georgetown University: Center on Education and the Workforce. 
Castells, M. (2010). The Rise of the Network Society (2nd edn). Malden, MA: Blackwell Publishing.

Cherry, M.A. (2009). Working for (virtually) minimum wage: applying the Fair Labor Standards Act in cyberspace. Alabama Law Review, 60(5), 1077-110.

Cherry, M.A. (2011). A taxonomy of virtual work. Georgia Law Review, 45(951).

Cherry, M.A. (2012). The gamification of work. Hofstra Labor \& Employment Law Journal, 40(4), 851-8.

Cherry, M.A. and Rogers, R.L. (2008). Prediction markets and the First Amendment. Illinois Law Review, 833(878-9).

Crain, M., Poster, W.R. and Cherry, M.A. (eds) (forthcoming). Invisible Labor. Berkeley, CA: University of California Press.

Edsforth, R. (2000). The New Deal: America's Response to the Great Depression. Hoboken, NJ: Wiley.

Ehrenreich, B. (2010). Nickeled and Dimed: On (Not) Getting By in America. New York: Henry Holt.

Epstein, R.A. (1994). Standing firm on forbidden grounds. San Diego Law Review, 31(1).

Epstein, R.A. (1995). Forbidden Grounds: The Case Against Employment Discrimination Laws. Cambridge, MA: Harvard University Press.

Glazer, E. (2011). Serfing the Web: sites let people farm out their chores. Wall Street Journal, 1 November.

Greenhouse, S. and Harris, E.A. (2014). Battling for a safer Bangladesh. New York Times, 22 April, B1, 8.

Howe, J. (2006). The rise of crowdsourcing. Wired, June, 176-8.

Irani, L. (2013). The cultural work of microwork. New Media \& Society, November, 1-20.

Irani, L. and Silberman, M.S. (2013). Turkopticon: interrupting worker invisibility in Amazon Mechanical Turk. CHI, April-May, 1-10.

Kalleberg, A.L. (2009). Precarious work, insecure workers: employment relations in transition. American Sociological Review, 74(February), 1-22.

Kimeldorf, H., Meyer, R., Prasad, M. and Robinson, I. (2006). Consumers with a conscience: will they pay more? Contexts, 5(1), 24-9. 
Kittur, A. et al. (2013). The future of crowd work. Proceedings of the 2013 Conference on Computer Supported Cooperative Work. ACM, 1301-18.

Lambert, S.J. (2012). When flexibility hurts. The New York Times, September, 1-3.

Lambert, S.J., Fugiel, P.J. and Henly, J.R. (2014). Schedule Unpredictability Among Early Career Workers in the US Labor Market: A National Snapshot (Vol. 15, pp. 1-4). Chicago, IL: University of Chicago. Accessed at https://ssascholars.uchicago.edu/sites/default/files/work-schedulingstudy/files/lambert.fugiel.henly_.precarious_work_schedules.august2014_0.pdf.

Levitan, S.A., Gallo, F. and Shapiro, I. (1993). Working But Poor: America's Contradiction. Baltimore, MD: Johns Hopkins University Press.

Marvit, M.Z. (2014). How crowdworkers became ghosts in the digital machine. The Nation, 2 February.

Mitchell, B. (1969). Depression Decade: From New Era Through New Deal, 1929-1941. New York: Harper \& Row.

Muhammad, A. (2011). Wealth and deprivation: ready-made garments industry in Bangladesh, Economic \& Political Weekly, XLVI(34), 23-7.

Nakamura, L. (2009). 'Don't hate the player, hate the game': The racialization of labor in world of warcraft. Critical Studies in Media Communication, 26(2), 128-44.

Newman, K.S. (2000). No Shame in My Game: The Working Poor in the Inner City. New York: Random House.

Pörtner, C.C., Toomim, M. and Hassairi, N. (forthcoming). Testing the theory of equalizing differences, using online labor market experiments. Accessed at https://www.dropbox.com/s/qpz428tc01euufn/turk-prelim-portner-14457.pdf.

Poster, W.R. (2013). Indian entrepreneurs, cybersecurity, and the global surveillance industry. Paper presented at the Annual Meeting of the Society for the Social Studies of Science, San Diego, CA.

Rejda, G.E. (2012). Social Insurance and Economic Security. Armonk, NY: M.E. Sharpe.

Reynolds, A. (2013). The water thief. In G. Dozios (ed.), The Year's Best Science Fiction: Thirtieth Annual Collection (pp. 415-25). New York: St. Martin’s Press. 
Ross, A. (2009). Nice Work if you can get it: Life and Labor in Precarious Times. New York: New York University Press.

Ross, J., Zalidivar, A., Irani, L., Tomlinson, B. and Silberman, M.S. (2010). Who are the crowdworkers? Shifting demographics in Mechanical Turk. Paper presented at CHI 2010, 10-15 April, Atlanta, GA.

Ross, W.G. (2005). When did the 'switch in time' actually occur? Rediscovering the Supreme Court's 'forgotten' decisions of 1936-37. Arizona State Legal Journal, 37(1153).

Stone, K.V.W. (2004). From Widgets to Digits: Employment Regulation for the Changing Workplace. New York: Cambridge University Press.

Stone, K.V.W. (2006). Legal protections for atypical employees: employment law for workers without workplaces and employees without employers. Berkeley Journal of Employment and Labor, 251(2), 251-86).

Stross, R. (2010). When the assembly lives moves online. New York Times, 30 October.

Tirado, L. (2014). Poor people don't plan long-term. The Observer, September, 1-10.

US Department of Labor (2001). Report on the American Workforce. Washington, DC: Bureau of Labor Statistics.

Vosko, L.F. (2006). Precarious Employment: Understanding Labour Market Insecurity in Canada. New York: McGill-Queen's University Press.

Warhurst, C., Carre, F., Findlay, P. and Tilly, C. (eds) (2014). Are Bad Jobs Inevitable? London: Palgrave Macmillan.

\footnotetext{
${ }^{1}$ Indeed, a working group of students at the Berkman Center for Internet and Society, Harvard Law School articulated ideas around improving cloudwork in 2011. The document, however, was never published. We credit the students as well as their professor, Jonathan Zittrain, for their dedication to this issue.

${ }^{2}$ Matthew Bingham and Joseph Dunn (2009) performed tasks on the Amazon Mechanical Turk and earned a little over \$2 for four hours' work.

${ }^{3}$ The complaint was filed as Otey v. Crowdflower, Inc., No. 3:12-v-05524-JST (N.D. Cal. 2013) and can be found online at http://www.leagle.com/decision/In\%20FDCO\%2020130618A76.

${ }^{4}$ The first author explored many of these issues in two full-length law review articles. See Cherry $(2009,2011)$.

529 U.S.C. $\$ 203(\mathrm{e})(1)$.

${ }^{6} 29$ U.S.C. $\$ 203(\mathrm{~g})$.

${ }^{7}$ See Katharine V.W. Stone (2006) for a list of factors from the cases. Often-cited cases on this subject include Rutherford Food Corp. v. McComb, 331 U.S. 722, $728-29$ (1947); Ira S. Bushey \& Sons, Inc. v. U.S., 398 F.2d 167 (2d Cir. 1968); Nationwide Mut. Ins. Co. v. Darden, 503 U.S. 318, 326 (1992).

${ }^{8}$ See, for example, Herman v. Express Sixty-Minutes Delivery Service, Inc., 161 F.3d 299 (5th Cir. 1998).

${ }^{9}$ See, for example, Richard A. Epstein $(1994,1995)$ arguing that most forms of regulation of the employment relationship, including minimum wage, should be banned.

${ }^{10}$ Miriam A. Cherry and Robert L. Rogers (2008) conclude that prediction markets, a collaborative technology on
} 
the Internet, should not be regulated by strict application of anti-gambling laws.

${ }^{11}$ While the Supreme Court had struck down earlier laws regulating the employment relationship under the 'freedom of contract' ethos, exemplified in Lochner v. New York, 198 U.S. 45 (1905), toward the midpoint of the Great

Depression, the court stopped striking down New Deal economic recovery legislation (Ross, 2005).

${ }^{12}$ See Fight for Fifteen Campaign's website at http://fightfor15.org/en/homepage/.

${ }^{13}$ Pörtner, Toomim and Hassairi, Testing the Theory of Equalizing Differences, Using Online Labor Market Experiments, available at https://www.dropbox.com/s/qpz428tc01euufn/turk-prelim-portner-14457.pdf. See also powerpoint at http://www.cs.washington.edu/affiliates/meetings/talks1213/toomimaffiliates12.pdf. 